\title{
Management of Vesicouterine fistulae during fistulae surgical caravan in Cote d'Ivoire
}

\author{
Djanhan L. E. ${ }^{1}$, Dia J. M. ${ }^{2 *}$, Menin M. M. ${ }^{1}$, Bohoussou E. ${ }^{2}$, Kouamé B. ${ }^{1}$, Samaké Y. ${ }^{1}$, \\ Kouakou K. P. ${ }^{1}$, Doumbia Y.1
}

\begin{abstract}
${ }^{1}$ Department of Obstetrics and Gynecology, Bouaké University Hospital, Bouaké, Cote d'Ivoire
${ }^{2}$ Department of Obstetrics and Gynecology, Treichville University Hospital, Abidjan, Cote d'Ivoire
\end{abstract}

Received: 20 October 2017

Accepted: 17 November 2017

\section{*Correspondence:}

Dr. Dia J. M.,

E-mail: jmlaminedia@yahoo.fr

Copyright: ( ) the author(s), publisher and licensee Medip Academy. This is an open-access article distributed under the terms of the Creative Commons Attribution Non-Commercial License, which permits unrestricted non-commercial use, distribution, and reproduction in any medium, provided the original work is properly cited.

\begin{abstract}
Background: The urogenital fistula (UGF) which designate a solution of continuity between the urinary and genital tracts in women, are divided into several entities of variable gravity. The objective of this study was to describe the epidemiological, clinical and therapeutic characteristics of patients treated for vesicouterine fistula during 'fistulas surgical caravans'.

Methods: This was a prospective and descriptive study on a cohort of 34 patients treated for Vesico-uterine fistulae during "fistulas surgical caravans " from $1^{\text {st }}$ January 2012 to $31^{\text {st }}$ December 2016.

Results: Vesico uterine fistulae represented $2.1 \%$ of all urogenital fistulae treated. At the time of occurrence of fistulas, the average age of the patients stay was 33.3 years, and the majority was not educated (88.2\%), lived in rural areas without occupations $(73.5 \%)$. All the fistulae were secondary to childbirth, the majority of which took place on a scarred uterus (67.6\%). And this childbirth responsible for the fistula was done by caesarean section in $97.7 \%$ of cases. Then the average duration of the fistula before management was 6 years. Finally, all the patients were operated by the same surgical technique, made by abdominal extra peritoneal transvesical way. The cure rate after this surgical technique was $97.1 \%$ (33 patients). The only case of failure required a second operation by another technique which permitted the healing of the patient.

Conclusions: The vesicouterine fistulae were rare and the satisfactory results of their management invite us to sustain these surgical caravans and ensure their widespread
\end{abstract}

Keywords: Diagnosis, Epidemiology, Vesico-uterine fistula, Treatment

\section{INTRODUCTION}

The urogenital fistula (UGF) which designate a solution of continuity between the urinary and genital tracts in women, are divided into several entities of variable gravity. The vesico vaginal fistulae (VVF) are the most common and the simplest. The most complex forms that are generally less frequent include: uretero-vaginal fistulae (UVF), recto-vaginal fistulae (RVF), vesico- uterine fistula (VFU) and the associated forms. In developing countries, the social exclusion they create, as well as the insufficient provision of care linked in part to the lack of local expertise, have dramatic physical and psychosocial consequences for the patients-mostly very young-affected with UGF. ${ }^{1,2}$ In Côte d'Ivoire, the management of the UGF was done in specialized departments of the University Hospital Centers, which are difficult to access for poor and rural patients. 
In order to widen the provision of care, the Ivorian authorities, since 2007 with the support of the United Nations Population Fund (UNFPA), have launched free local surgical caravans in rural areas. These caravans also help to train health professionals and provide the regions visited with technical equipment for the care and repair of UGF.

During these 'surgical caravans UGF', we had the opportunity to take care of patients suffering from UVF, known as rare and of iatrogenic etiology. It seemed therefore appropriate for us to report our experience on this subject through this study with the aim to describe the epidemiological, clinical and therapeutic characteristics of the patients.

\section{METHODS}

It was a prospective and descriptive cohort study conducted from January $1^{\text {st }} 2012$ to December $31^{\text {st }} 2016$ (5 years) on patients treated for UGF during 'fistula surgical caravan " in Cote d'Ivoire.

All the patients treated for VUF during these caravans were included in the study. The parameters studied were the socio-demographic, clinical and therapeutic characteristics, of the patients. Data collection was done from a survey sheet through individual interviews and direct observation of lesions during physical examinations during consultations and surgeries.

The data were analyzed using the Epi Info 7, Excel and Word software.

\section{Procedure of "fistulae surgical caravans" in Ivory Coast}

\section{Site and rhythm of caravans}

These caravans were held in 7 care sites erected by the Ministry of Public Health in collaboration with the UNFPA. These sites were located within existing hospital structures, namely the University Hospital Center of Bouaké, and the Regional Hospital Centers of Bondoukou, Man, Gagnoa, Séguéla, Korhogo and San Pédro (Figure 1).

And in the year 12 caravans are expected on a one caravan per month for a period of 10 days.

\section{Management team}

The care of the patients during each caravan was composed of, a mobile team of three trainers: an expert surgeon of the Fistula project and two university professors (urologists and gynecologists-obstetricians); and professionals to be trained (Gynecologistsobstetricians, surgeons, nursing specialists and midwives) from the visited site ("local team") and other health regions.

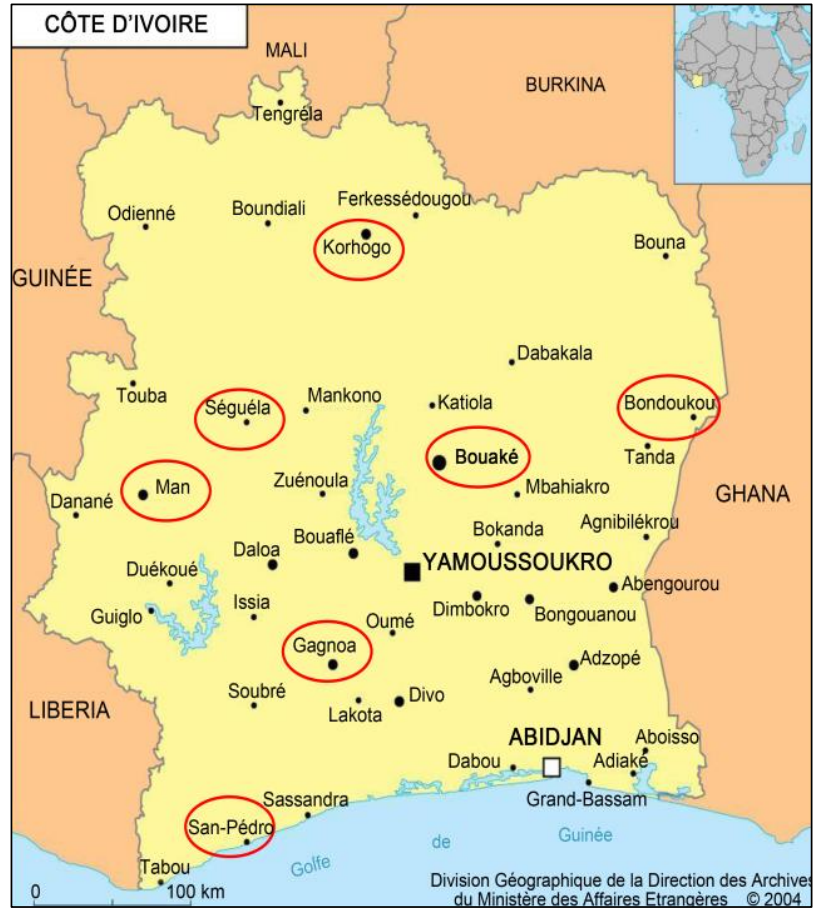

Figure 1: Map of Côte d'Ivoire with localization support sites.

\section{Patient selection}

Patients were pre-selected by local surgical teams and then assessed by the entire caravan team.

The preoperative evaluation included a complete clinical examination, urogynecological examination using valves with or without methylene blue to determine the site of the fistula.

Methylene blue is injected into the bladder from the urethra with a urinary catheter and the exit of the colorant by the uterine cervix signs the communication between the two cavities (uterine and bladder). In addition, no paraclinic diagnostic tests were performed.

\section{Treatment of VUF}

The patients received free reconstructive surgery under general or locoregional anesthesia.

\section{Post-operative follow-up}

At the end of the intervention a post-surgical bladder drainage is held in place for 21 days without complications. The post-operative follow-up was carried out by the local medical team.

Therapeutic results were assessed after 1 month, 2 months and 3 months follow-up. All patients with closed fistula (dry patients) with no sphincter disorders or urinary incontinence were cured. 


\section{RESULTS}

\section{Epidemiological characteristics}

Frequency of VUF

During the study period, we collected 34 cases of VUF out of 1592 UGF treated, a frequency of $2.1 \%$ compared to all the UGF.

Socio-demographic characteristics at the occurrence of the fistula

The average age of patients was 33.3 years (extreme 1643 years) and $82.3 \%$ (28 patients) had more than 30 years. Moreover, all the 25 patients living in rural areas were unemployed and because of the fistula 14 patients (41.2\%) were abandoned by their spouses and 9 (26.5\%) lost their jobs.

Table 1: Distribution of patients according to the socio-demographic characteristics at the occurrence of the fistula.

\begin{tabular}{|lll|}
\hline $\begin{array}{l}\text { Socio-demographic } \\
\text { characteristics }\end{array}$ & Population & Percentage \\
\hline Age (years) & & \\
\hline$\leq 18$ & 2 & 5.9 \\
\hline $19-29$ & 4 & 11.8 \\
\hline $30-39$ & 20 & 58.8 \\
\hline$>39$ years & 8 & 23.5 \\
\hline Total & 34 & 100 \\
\hline Level of education & & \\
\hline Not educated & 30 & 88.2 \\
\hline Primary & 2 & 5.9 \\
\hline Secondary & 2 & 5.9 \\
\hline Total & 34 & 100 \\
\hline Parity & & \\
\hline Primiparous & 5 & 14.7 \\
\hline Pauciparous & 8 & 23.5 \\
\hline Multiparous & 21 & 61.8 \\
\hline Total & 34 & 100 \\
\hline Profession & & \\
\hline Housewives & 25 & 73.5 \\
\hline Civil servant & 2 & 5.9 \\
\hline Trader & 7 & 20.6 \\
\hline Total & 34 & 100 \\
\hline & & \\
\hline
\end{tabular}

\section{Etiopathogenic characteristics}

All our patients reported that their VUF had occurred after childbirth and some had a history of obstetric surgery.

\section{History of obstetrical surgery}

Of the 34 patients, $67.6 \%$ (23 patients) had a history of obstetric surgery (cicatricial uterus) prior to delivery responsible for the fistula: 14 had a caesarean history and 9 a history of uterine rupture.

\section{The circumstances of occurrence of VUF}

The work of delivery responsible of the fistula was led by an unqualified agent (traditional birth attendants and nurses) in $67.7 \%$ of cases.

Table 2: Distribution of patients according to circumstances of occurrence of VUF.

\begin{tabular}{|c|c|c|}
\hline $\begin{array}{l}\text { Circumstances of } \\
\text { Occurrence VUF }\end{array}$ & Population & Percentage \\
\hline \multicolumn{3}{|c|}{$\begin{array}{l}\text { Quality of the agent responsible for the follow up of } \\
\text { the labour at the occurrence of fistula }\end{array}$} \\
\hline Traditional birth attendants & 21 & 64.7 \\
\hline Midwives & 7 & 21 \\
\hline Gynecologists & 4 & 12 \\
\hline Nurses & 1 & 3 \\
\hline Total & 34 & 100 \\
\hline \multicolumn{3}{|c|}{ Labour duration at the occurrence of fistula } \\
\hline$<1$ day & 7 & 20.6 \\
\hline$>1$ day & 27 & 79.4 \\
\hline Total & 34 & 100 \\
\hline $\begin{array}{l}\text { Mode of delivery during } \\
\text { occurrence of fistula }\end{array}$ & Effective & Percentage \\
\hline $\begin{array}{l}\text { Caesarean sections in } \\
\text { emergency }\end{array}$ & 33 & 97.1 \\
\hline Instrumental extraction & 1 & 2.9 \\
\hline Total & 34 & 100 \\
\hline
\end{tabular}

Table 3: Distribution of patients according to clinical characteristics of the VUF.

\begin{tabular}{|c|c|c|}
\hline $\begin{array}{l}\text { Clinical characteristics of } \\
\text { VUF }\end{array}$ & Effective & Percentage \\
\hline \multicolumn{3}{|c|}{ Duration of the fistula evolution (years) } \\
\hline$<1$ & 9 & 26.5 \\
\hline $1-5$ & 7 & 20.6 \\
\hline $5-10$ & 12 & 35.3 \\
\hline$>10$ & 6 & 17.6 \\
\hline Total & 34 & 100 \\
\hline \multicolumn{3}{|l|}{ Symptomatic signs } \\
\hline Isolated urinary losses & 3 & 8.8 \\
\hline $\begin{array}{l}\text { Urinary loss and cyclic } \\
\text { hematuria }\end{array}$ & 31 & 91.2 \\
\hline Total & 34 & 100 \\
\hline \multicolumn{3}{|c|}{ Size of the fistula (intraoperative) } \\
\hline Average $(2-3 \mathrm{~cm})$ & 14 & 41.2 \\
\hline Small $(<2 \mathrm{~cm})$ & 20 & 58.8 \\
\hline Total & 34 & 100 \\
\hline
\end{tabular}

\section{Clinical characteristics}

The average duration of the fistula progression prior to management was 6 years (extreme 8 months to 15 years). 


\section{Therapeutic characteristics}

\section{Surgical technique}

All our patients underwent a surgery performed under general anaesthesia in $58.8 \%$ of cases (20 patients) and under spinal anaesthesia in $41.2 \%$ (14 patients).

The surgical technique was standard (the same in all patients) performed by abdominal, extra peritoneal and transvesical way according to the following steps: Cystotomy, the catheterisation of the ureters, the detachment of the bladder from the uterus, location of the fistula and revivification of its edges, and then the suture, without stretching, of the vesical and vaginal orifices.

After the intervention, the post-surgical bladder drainage was held for 21 days in all the patients. One patient underwent a second surgery according to the method of Martius which consisted of an interposition of a vascularized and pedicled epiploic flap between the bladder and the uterus after closure of uterine and bladder breaches. ${ }^{3}$

\section{Results of treatment}

After 3 months of surveillance after standard surgery, the cure rate was $97.1 \%$ (33 patients) compared to only 1 case of failure. This failure was found at the first control and the second surgery according to the method of Martius performed 6 months later helped her recovery. ${ }^{3}$

\section{DISCUSSION}

\section{Epidemiological characteristics}

\section{Frequency of VUF}

The VUF are unusual representing the rarest entity UGF: 1 to $4 \%$ of UGF. ${ }^{4,5}$ Several publications have confirmed the scarcity through series generally on less numerous populations or clinical cases. ${ }^{6-9}$

In the present study this affection was also rare because we collected only 34 cases in 5 years representing $2.1 \%$ of fistulae that we had treated. However, it is possible that many more cases will be in our country because the fistulas are often hidden affections and caravans do not cover the entire Ivorian territory.

Besides the discovery of the VUF exposes the limits of our emergency obstetric care system and invites us to develop and maintain eradication measures, which should focus on the socio-demographic profile of the patients and the identification of etiologies.

\section{Socio-demographic characteristics}

Concerning socio-demographic profile at the time of occurrence of the VUF, the majority of our patients were aged over 30 years $(82.3 \%)$, multiparous $(61.8 \%)$, noneducated $(88.2 \%)$ and lived without profession in rural areas $(73.5 \%)$.

In our country the majority of rural areas has no health center able to offer comprehensive emergency obstetric care (availability of an operating theater with qualified staff). Faced with this deficit we recommend the adoption one of the efficient strategies to fight against obstetric accidents (like fistulas), which consists in providing women at risk with family planning services. So, after the care of our patients we sent those who were not menopausal to family planning services. But also in the interest of primary prevention of fistula, we recommend the use of contraceptive measures in women with the same socio-demographic profile as our patients.

The second strategy dictated by the epidemiological profile of our patients is to sustain surgical caravans nearby rural areas, and especially to extend them beyond the seven health regions. And in the best case, they must be quickly replaced by permanent services.

Furthermore, many patients in this study reported having been abandoned by their spouses $(41.2 \%)$ and lost their jobs $(26.5 \%)$ due to the fistula. In developing countries, some authors have also focused on social exclusion and its dramatic consequence in patients with fistula. ${ }^{1,2}$ Caravans provide a solution to this problem by increasing the care free of charge

\section{Etiopathogenic characteristics}

In the present series, all the fistulas were secondary to childbirth which took place on a scarred uterus in general $(67.6 \%)$. And this birth responsible for the fistula was done by Caesarean section in the majority of cases $(97.7 \%)$. In the literature cesarean section is cited as the main cause of the VUF, because of a lack of vesico uterine detachment. ${ }^{4,10,11}$ When performed on a cicatricial uterus, the risk of VUF increases, especially in situations of extreme urgency.

In the present study, we found that the majority of patients $(64.7 \%)$ had been monitored by unqualified birth attendants during labor that had lasted more than a day in $79.4 \%$ of cases. This practice is common in our developing countries has also been reported by Kaboré in his series. These low-skilled persons aggravate the situation bringing the obstetrician to perform his caesarean in extreme emergency that may facilitate the occurrence of the VUF. Under these conditions the VUF could be linked to a fall of eschar or an iatrogenic wound passed unnoticed.

Indeed, during obstructed labor, unqualified birth attendants by ignorance could allow the situation to continue, and thus favor the formation of a bladder ischemia created by compressing it on the pubic 
symphysis by the fetal head. The ischemia will progress to eschar whose fall will cause fistula., ${ }^{4,13}$

\section{Clinical characteristics}

In the present study, the average duration of the VUF was 6.03 years (extreme 1 year to 30 years). Loué found a similar average duration (6 years). ${ }^{8}$ For Bohoussou these long delays in disease progression are the result of the combination of several factors: dissimulation of the disease, ignorance of the existence of treatment by the patients, lack of financial resources, misdiagnosis and insufficiency of qualified human resources and structures with a good health technical platform for the treatment. ${ }^{14}$

Regarding the symptomatic signs, all of our patients have consulted for losses of urine which remain the most frequent reason for consultation in UGF. But in the majority of cases $(91.2 \%)$, these urine losses were associated with cyclic hematuria.

This clinical form was also found by Moussaoui and Sulla in the majority of their patients. ${ }^{15,16}$

To confirm the diagnosis, we limited to the test with methylene blue, which is a simple noninvasive clinical examination, inexpensive, readily available in our resource-limited countries. As for the injuries themselves, they were visualized intraoperatively and in most cases $(58.8 \%)$ they were small sizes characterised by the diameter of their orifices less than $2 \mathrm{~cm}$.

\section{Therapeutic characteristics}

Spinal anesthesia was the type of anesthesia most used $(41.2 \%)$. It is inexpensive, easier to set up in poorly equipped centers. In the present series, the treatment was essentially surgical, and the abdominal extra peritoneal way was used in all the cases. This approach also practised by Taika, had the advantage, after opening the bladder, of easily identifying ureteral meats and assessing their situation in connection with the fistula. ${ }^{17}$ This action prevented injury to the ureters during bladder-uterus dissection. This technique is easy to run and reproducible unlike the transperitoneal way which is hard and has a high risk of injury to the ureters.

Technically speaking, our basic procedure was the bladder-uterus detachment, revivification of its edges and then suture without tension in two plans. Some authors advocate in addition, the interposition of the omentum or peritoneum vesicouterine between the bladder and uterus. ${ }^{17,18}$ According to these authors the interposition would strengthen the closure of the fistula.

After the standard surgery the bladder drainage of our patients was maintained over 21 days. And after removal of the urinary catheter the cure was declared when patients no longer had urinary loss and were continent after a monitoring 3 month. So, we got a cure rate of
97.1\% (33 patients), comparable to the cure rates observed by El Moussaoui and Taika in their series. ${ }^{15,17}$ The only failure after standard surgery, has been subject to a second surgery by the method of Maritius which allowed to obtain the cure of the patient. ${ }^{3}$

\section{CONCLUSION}

Although rare, vesico-uterine fistulas have been encountered during fistula caravans in our country. The satisfactory results of their care invite us to perpetuate these surgical caravans and to ensure their passage to scale. Moreover this pathology can be avoided by improving and enhancing access to emergency obstetric care, by extending the family planning coverage and by training and sensitizing health care providers for better caesarean section.

\section{Funding: No funding sources}

Conflict of interest: None declared

Ethical approval: The study was approved by the Institutional Ethics Committee

\section{REFERENCES}

1. Kaboré AF, Kambou T, Ouattara A, Zango B, Yaméogo C, Kirakoya B, et al. Epidemiology, etiology and psychosocial impact of urogenital fistulas in a cohort of 170 consecutive patients managed in three treatment centers in Burkina Faso from 2010 to 2012. Prog Urol. 2014;24:526-32.

2. Schlienger G, Laroche J, Karsenty G, Bertrand S, Dulac JP, Fournier R, et al. Obstetrical Vesicovaginal fistula for single visiting surgeons in Africa. Medicine and Tropical Health. 2012;22:12630 .

3. Martius H. The operative restoration of the totally missing urethra and the shooting muscle of the same. Central Blu Gynakol. 1928;52:480.

4. Baumet M. Vesico-uterine fistulas J. Chir. 1975;110:307-16.

5. Benchekroun A, Lacklar A, Soumana A, Farik M.H.

6. Vesico-uterine fistulas: about 30 cases. Ann Urol. 1999;33:75-9.

7. Trabelsi N, Makni MY, Guermazi H, Boujnah H, Zmerli S. Vesico-uterine fistulas: about 6 cases. Ann Urol. 1989;23:113-6.

8. Drissi M, Karmouni T, Tazi K, Khader EK, Koutani A, Attya IA, et al. Vesicouterine fistulas: an experience of 17 years. Prog Urol. 2008;18(3):173-6.

9. Loué V, Traore M, Koffi A, Adjoby R, Kouame A, Akpa Y, et al. Obstetric Vesicouterine fistulas: about 26 cases managed at Cocody's University Hospital. J Gynecol Obstet. 2017;5(1):20-4.

10. Onsrud M, Sjoveian S, Mukwege D. Cesarean delivery-related fistulae in the Democratic Republic of Congo. Int J Gynecol Obstet. 2011;114:10-4.

11. Lenkovsky Z, Poded D, Shapiro A, Caine M. Vesicouterine fistula: a rare complication of cesarean section. J Urol. 1988;139:123-5. 
12. Ozmen E, Yal C, Gulhan N, Unal S. Vesico-uterine fistula (Youssef's syndrome): case report. Int Urol Nephrol. 1998;30:451-3.

13. Afriat R, Casanova JM, Bercau G, Sauvanet E, Freund M, Bidat L. Vesico-uterine fistula occurring after normal delivery ina woman with previous cesarean section. J Gynecol Obstet Biol Reprod. 1997;637-40.

14. Lugagne PM, Leo JP, Richard F. Uro-genital fistulas. EMC Gynecol. 1996;220(A10):5.

15. Bohoussou E, Kouamé B, Lebeau R, Saki C, Yao I, Okon G, et al. Vesico-vaginal fistula of obstetric origin: about 68 cases taken charge at the hospital of man (Ivory Coast). Journal de la SAGO. 2015;6(2):11-5.

16. El Moussaoui A, Aboutaie R, Bennani S, Elmrinim, Meziane F, Benjelloun $S$. Les fistules vésicoutérines. J Urol. 1994;100:143-6.
17. Sylla C, Fall A, Diallo A, Ndoya A, Ba M, Gueye S, et al. Vesico-uterine fistulae. Report of 5 cases. Prog Urol. 2000;4(10):634-7.

18. Taika A, Kamal EM, Aboutaieb R, Samouh N, Himmi A. Youssef's syndrome. Prog Urol. 2001;11:78-81.

19. Issa M, Schmid HP, Stamey TA. Youssef's syndrome: Preservation of uterine function with subsequent successful pregnancy following surgical repair. Urol Int. 1994;52:220-2.

Cite this article as: Djanhan LE, Dia JM, Menin MM, Bohoussou E, Kouamé B, Samaké Y, Kouakou KP, Doumbia Y. Management of Vesicouterine fistulae during fistulae surgical caravan in Cote d'Ivoire. Int J Reprod Contracept Obstet Gynecol 2018;7:37-42. 